\title{
Chinese Traditional Aesthetics in Qing Palace Drama*-Take "Story of Yanxi Palace" as an example
}

\author{
Han Mao ${ }^{\dagger 1, a}$, Jingru Liu ${ }^{1, b}, Z$ ihan $\mathrm{Qu}^{2, \mathrm{c}}$ \\ ${ }^{1}$ School of Architecture and Art Central South University Changsha Hunan China \\ ${ }^{2}$ School of Arts Chongqing University Chongqing China
}

\begin{abstract}
Among the TV series that emerged in the summer of 2018, Yu Zheng's "Story of Yanxi Palace" was the most popular, and it continued to surpass "Ruyi's Royal Love in the Palace" (a court drama of the same type), with a wide range of influence and a high degree of discussion. This article attempts to explore the spiritual beauty of the plot, the exquisite beauty of costumes and the quaint beauty of the pictures through analyzing the plot, costumes, props, shots and other visual content of the drama from an aesthetic perspective.
\end{abstract}

\section{Introduction}

In recent years, with the popularization of television and the Internet, the number of TV dramas has exploded. Among the numerous TV dramas, court dramas have been popular among audiences, as far as "War And Beauty" and "Princess of Pearl", etc. Recently, "Empresses in the Palace" and "Treading On Thin Ice" have been praised by the audience to varying degrees. In the summer of 2018, the popularity of "Story of Yanxi Palace" directed by Yu Zheng rose sharply, becoming a leader in court dramas over the same period. The audience said that the plot, character settings, props, and pictures in the TV series are all "beautiful".

\section{The Beauty of the Plot and the Character}

In ordinary court dramas, the protagonist is very kind at first. In the TV series "The Legend of Zhen Huan" in previous years, the protagonist's expression was smiling when he appeared on the stage, but in "Story of Yanxi Palace", the protagonist's first appearance was a pocker face (Figure 1). Moreover, the plot of "Story of Yanxi Palace" has developed extremely fast. All the characters that conflict with the protagonist have been sanctioned. The first "villain" that appeared even played less than five minutes, which also laid the foundation for the protagonist's character setting. As the plot develops, the promotion of the protagonist's status seems to be very smooth. (Figure 2), the rapid change of identity implies the rapid development of the plot. The protagonist's status jumped from the bottom to the top. This kind of plot similar to "flying to the branches to become a phoenix" allows the audience to vent their anxiety in life, which is in line with the public's aesthetic taste. The specific

\footnotetext{
aaohanhan@foxmail.com

bkirakira0.0@qq.com

c109599279@qq.com
}

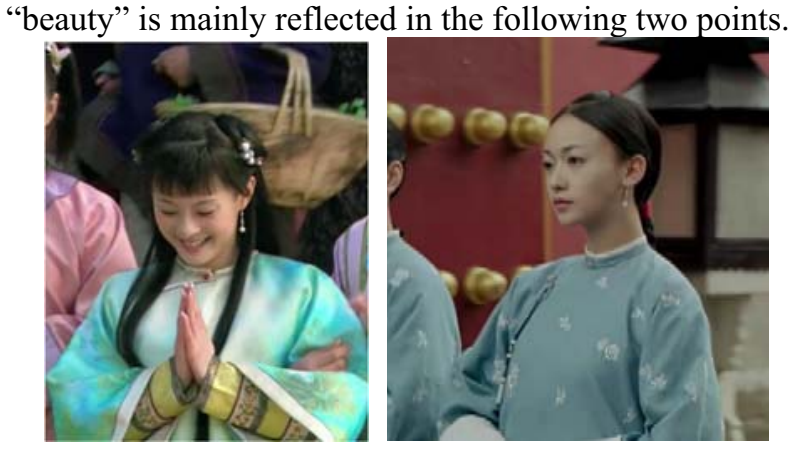

Figure 1: The protagonist's first shot comparison

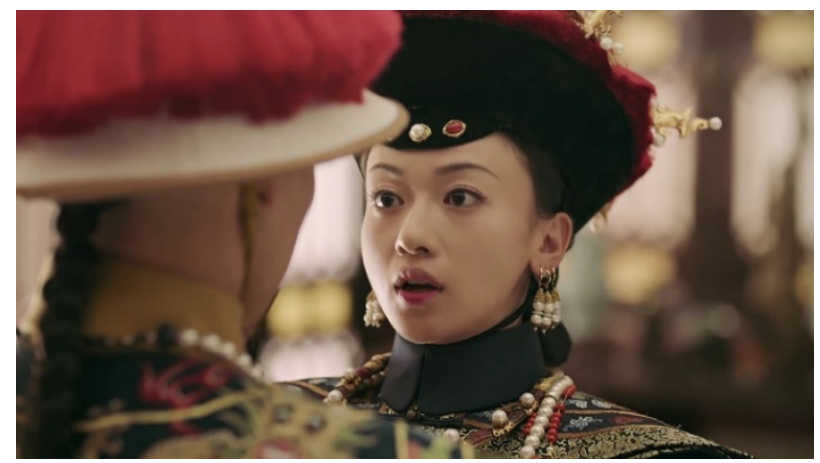

Figure 2: Protagonist role change

\subsection{The Dialectical Relationship between Good and Evil}

In the Outline of the History of Chinese Aesthetics, Mr. Ye Lang said that "the things of beauty and ugliness are not pure and absolute." The TV series embodies the symbiotic relationship between good and evil by creating characters. The role in the TV series - "Imperial Noble Consort Gao" (Ningxin Gao), looks like a bad person, but as the plot develops, the audience will find that this role actually has 
its own difficulties; Imperial concubine Xian (Figure 3), she was kind and cautious in the early stage, but as the plot developed, she became a villain.
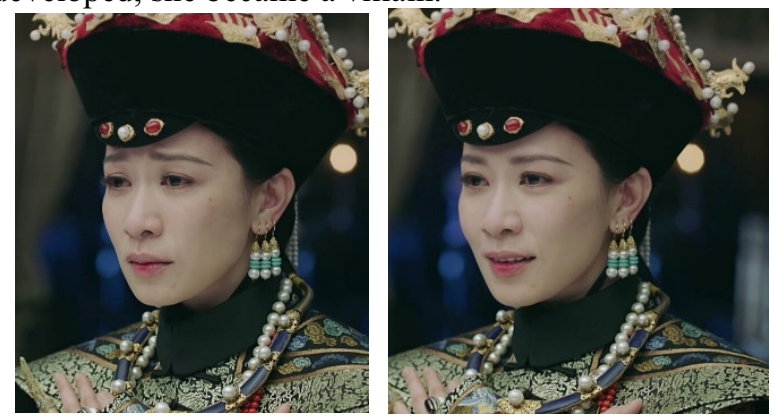

Figure 3: Imperial concubine Xian in lens before and after comparison

\subsection{Rational Rebellion}

The shaping of individual aesthetics is an important method to attract the audience's attention. TV dramas firmly attract audiences by creating unique characters. In "China Aesthetics", Mr. Li Zehou pointed out that the Qing Dynasty's thinking tends to be free and liberated, beauty is in "life", people's autonomous consciousness is awakened, and "spirituality" has become the theme of aesthetics. The most typical character in the TV series is the protagonist "Wei Yingluo". "In such an environment, it is better to regard Wei Yingluo as the awakening of feminism than as an individual's awakening." "Me, Wei Yingluo, is naturally grumpy and not easy to mess with." (Figure 4) has become a hot topic on the Internet. This is also the most obvious manifestation of her self-conscious awakening. "Tooth for tooth" has become her representative word. Her personality is distinct and unique, free and unrestrained.
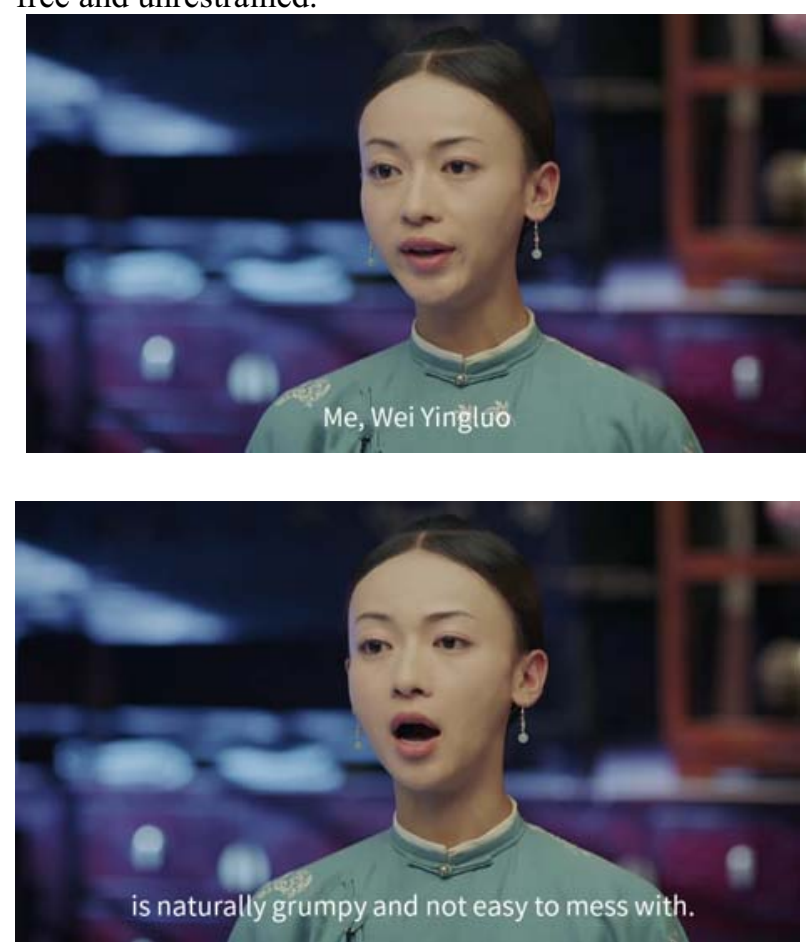

Figure 4: Protagonist's lines

\section{Exquisite Costume Props and Makeup}

Mr. Jin Danyuan pointed out in "New Theory on TV Aesthetic Culture": "The people who write historical dramas and costume dramas should have a certain sense of historical responsibility and social responsibility." The producer uses a large number of traditional Chinese skills on costumes and props, and clears them. The popular makeup of the generation is restored to the face of the actor, restoring the historical style of the Qing Dynasty to the greatest extent. Compared with the palace drama "Ruyi's Royal Love in the Palace" that was released in the same period, it is also a budget of more than 300 million yuan. The total salary of the actors in "Story of Yanxi Palace" has been compressed to less than half of the protagonist's salary in "Ruyi's Royal Love in the Palace". This shows that the production People's care in costume props. (Figure 5)

\begin{tabular}{|c|c|c|}
\hline & Story of Yanxi Palace & $\begin{array}{c}\text { Ruyi's Royal Love in the } \\
\text { Palace }\end{array}$ \\
\hline $\begin{array}{c}\text { Shooting } \\
\text { cost }\end{array}$ & Nearly 300 million & $\begin{array}{c}300 \text { million to } 400 \\
\text { million }\end{array}$ \\
\hline Actor pay & 24 million(Total pay) & $\begin{array}{c}53.5 \text { million(Actress } \\
\text { pay) }\end{array}$ \\
\hline $\begin{array}{c}\text { Data } \\
\text { Sources }\end{array}$ & $\begin{array}{c}\text { Weibo @Character Yu } \\
\text { Zheng Interview }\end{array}$ & $\begin{array}{c}\text { The Beijing News, } \\
\text { Phoenix Netws }\end{array}$ \\
\hline
\end{tabular}

Figure 5: Comparison of budget between "Strategy of Yanxi Palace" and "Ruyi's Royal Love in the Palace"

\subsection{Exquisite Retro Costumes and Props}

The costumes in the play are all hand-sewn by dedicated personnel, and the production of some props (such as k'ossu round fan, velvet flower headwear, etc.) is instructed and hand-made by inheritors of traditional Chinese skills. In the TV series, each concubine's clothing is tailor-made and hand-sewn by the embroiderer. The embroidery techniques used include seed embroidery, pan-gold embroidery, bead embroidery, and hand embroidery (Figure 6). In addition to the exquisite handwork, the style is also very elegant. (Figure 6) (Figure 7).

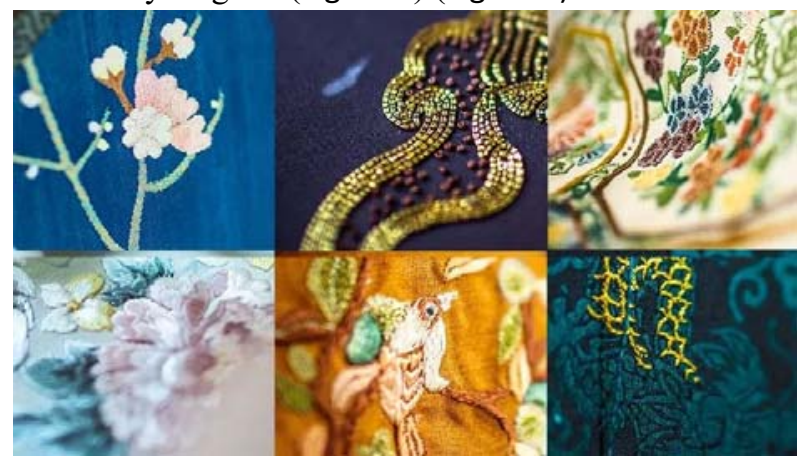

Figure 6: Intangible cultural heritage displayed in TV series 

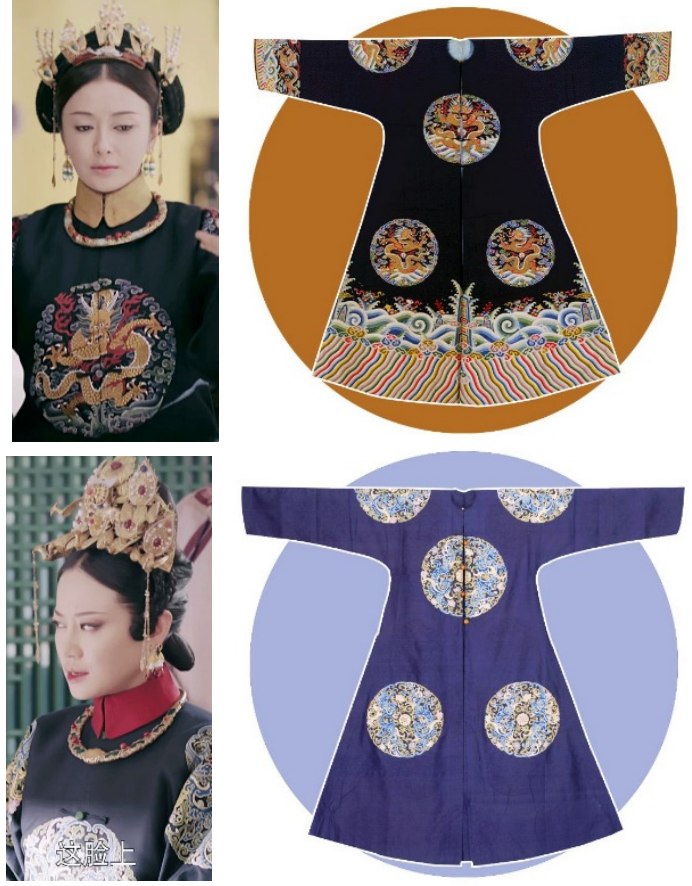

Figure 7: Costumes in TV Series

The crew is also very serious about props. The various velvet headdresses enrich the screen effects of the characters in the TV series. In order to purchase velvet ornaments, the crew specially invited Mr. Zhao Shuxian, the non-genetic inheritor of Nanjing velvet, to bring his apprentices. Each concubine is also holding a K'o-ssu craft round fan. Among them, the round fan in the hands of the "Noble Concubine Gao" completely restores the cultural relics of the Palace Museum (Figure 8). In the preparation of the tapestry-related props, the crew invited the craftsman, Gu Jiandong, the inheritor of Suzhou K'ossu skills, to guide the tapestry production. The loom in the weaving scene is also a real tapestry machine (Figure 9).

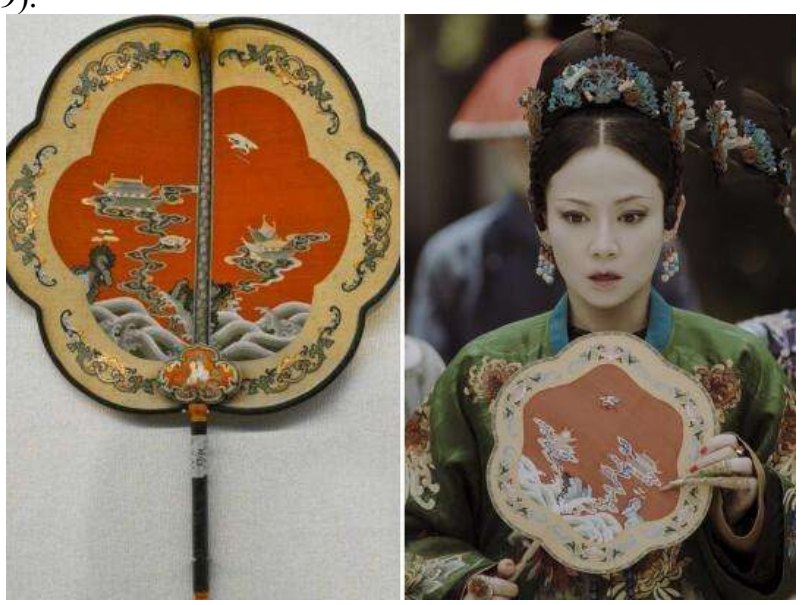

Figure 8: Intangible cultural heritage displayed in TV series

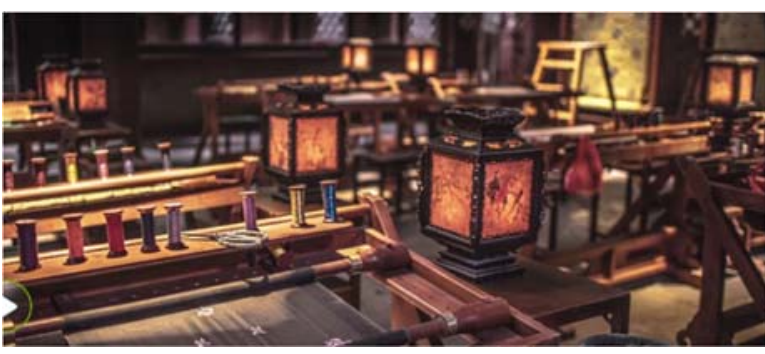

Figure 9: Weaving scene

\subsection{Highly Restored Ancient Makeup Face}

The makeup in the play is fresh and elegant, which is highly similar to the ancient paintings of the Qing Dynasty. The lip makeup is similar to the popular "lip biting makeup" in previous years. In fact, this comes from the popular lip makeup in the Qing Dynasty (Figure 10). Such lip makeup makes the characters more feminine and beautiful, visually reduces the dynamics of the lips when speaking, and makes the characters more dignified. The eyebrow shape is similar to the traditional Chinese "willow leaf eyebrow" and adjusted according to the personalities of different characters in the TV series. The characters in the TV series are elegant and smart.

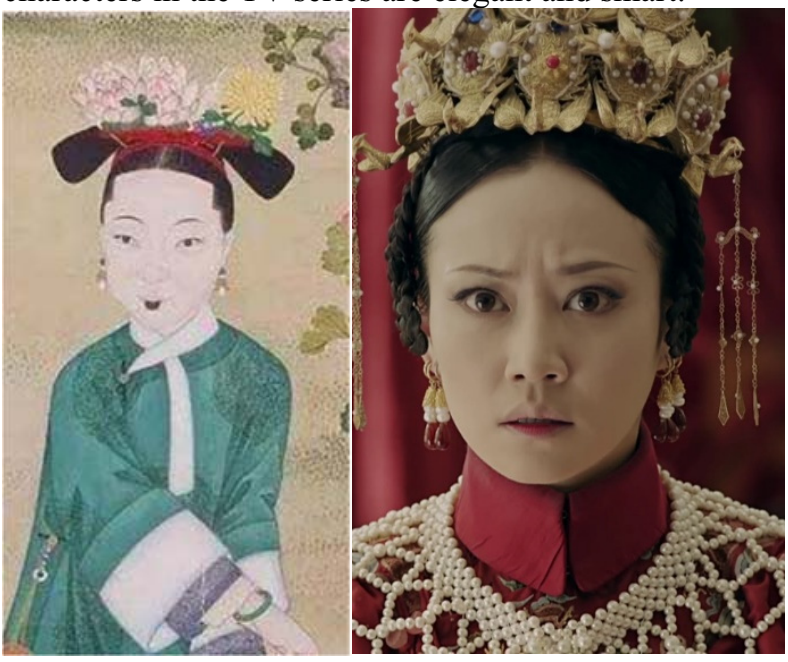

Figure 10: Qing Dynasty Ancient Paintings and roles in TV series

\section{Quaint Picture Performance}

Wang Xiaoshu summed up the aesthetic characteristics of the Qing Dynasty in the History of Chinese Aesthetic Culture: Yuan Ming Qing Volume _ " The most prominent Xi Shang can be cited in the Qing Dynasty is to follow and emulate the behavior of the ancients, that is, to take elegance as beauty."

A large number of traditional symmetrical compositions, and the color matching inspiration of ancient paintings in the Qing Dynasty reflect the retro elegance of the TV series. The producer of "Story of Yanxi Palace" explored and tried traditional Chinese aesthetics. Compared with the colorful TV drama scenes (Figure 11 and 12) taken by the producer in the early stage, the scenes of "Story of Yanxi Palace" (Figure 13) have a completely 
different style: lower saturation reduces the visual stimulation of the audience, Exquisite costume props and pictures bring viewers visual enjoyment, and such pictures bring freshness to the audience.

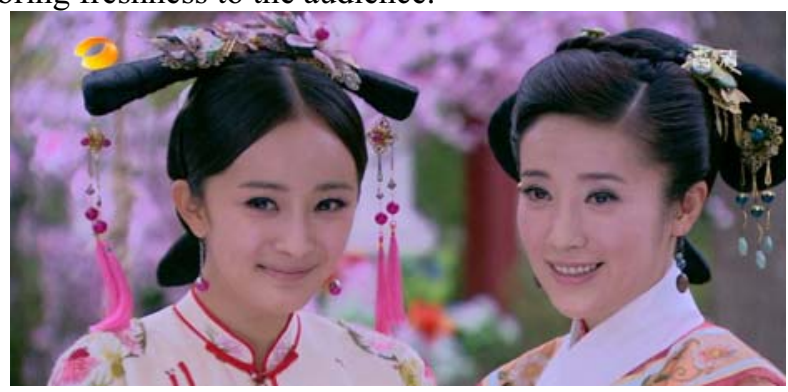

Figure 11: Stills of "Jade Palace Lock Heart"

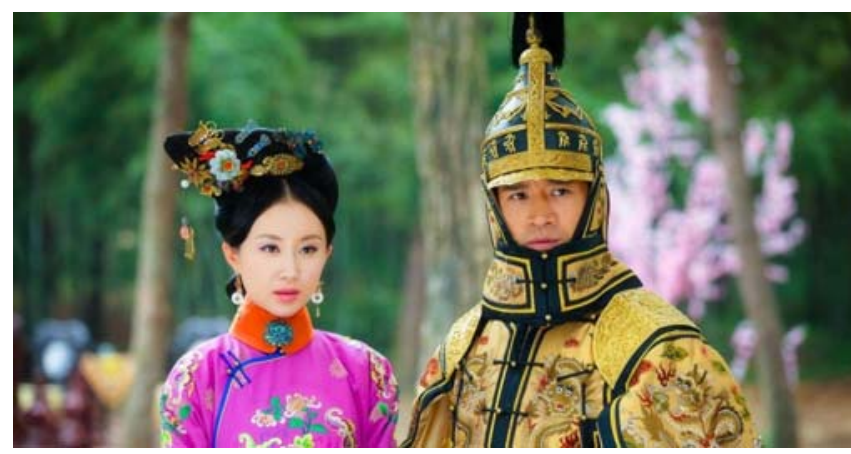

Figure 12: Stills of "Palace3: The Lost Daughter"

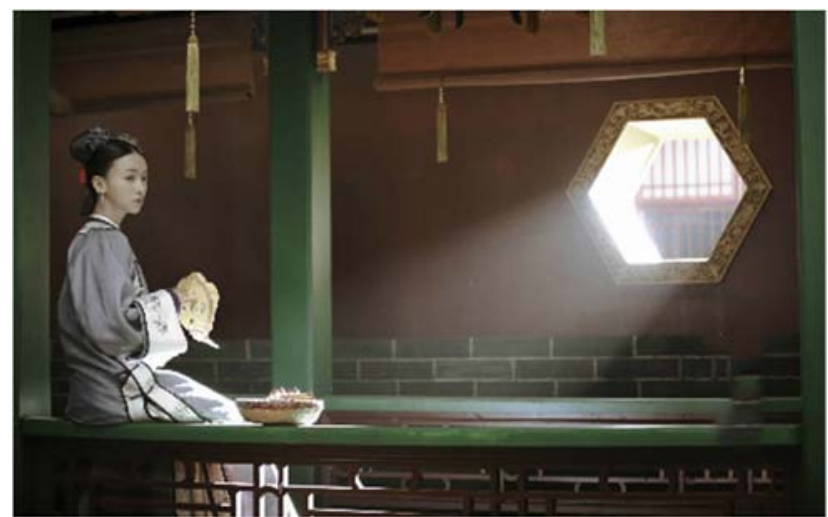

Figure 13: Stills of "Story of Yanxi Palace"

\subsection{Chinese Traditional Symmetrical Composition}

In "Strategy of Yanxi Palace", a large number of symmetrical composition is used, and the picture is dignified and elegant. Especially in large scenes, the symmetrical composition gives the audience a majestic and grand visual experience. The lens is modified or echoed in details on the basis of a large area of symmetry on the left and right, which not only enriches the details, but also deepens the visual effect. In traditional Chinese architecture and traditional patterns, the shape and composition are often symmetrical, and the traditional charm of the Golden Mean is reflected in such composition ideas. (Figure 14)

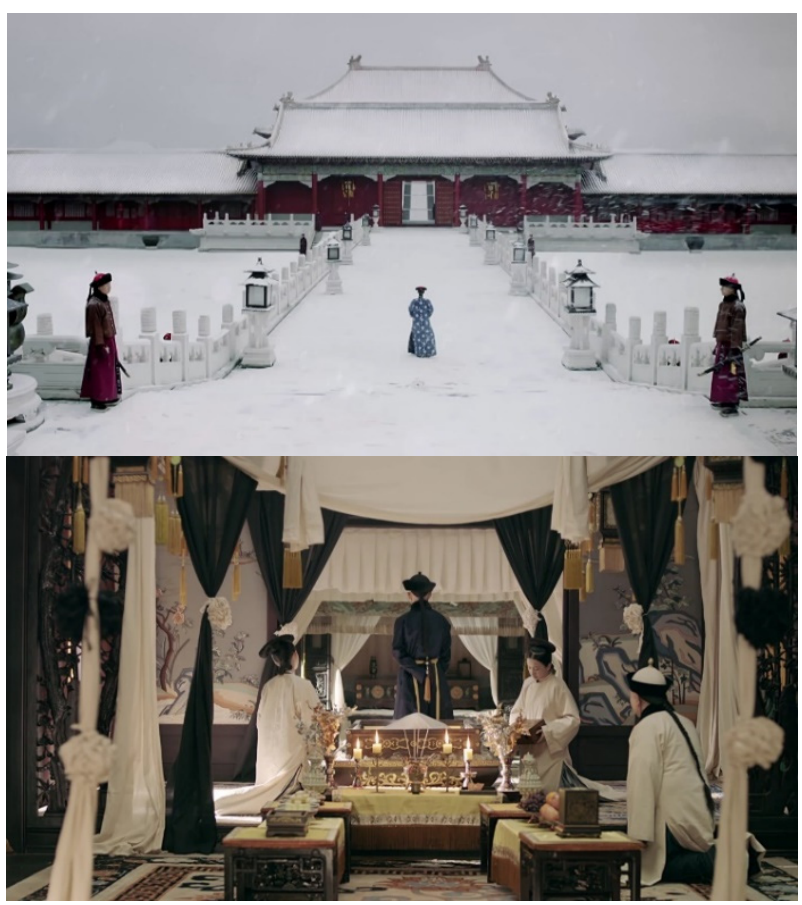

Figure 14 Picture composition

\subsection{Ancient and Elegant Color}

The color tones in the TV series are very simple and elegant after color adjustment (Figure 15), and the adjustment of the color tones tends to the aesthetic trend of "retro and elegant" in the Qing Dynasty. Yu Zheng mentioned in his Weibo that the color design inspiration of color director Sun Ting was an ancient painting of the Qing Dynasty. (Figure 16), she also mentioned in her article: "According to the unique texture presented by the wheatish background of ancient paintings, the wheatish background was added to the color scheme of 'Story of Yanxi Palace',... On the basis of the inherent colors of the picture, layer by layer, other colors are added and matched to form the texture of the ancient paintings seen today."

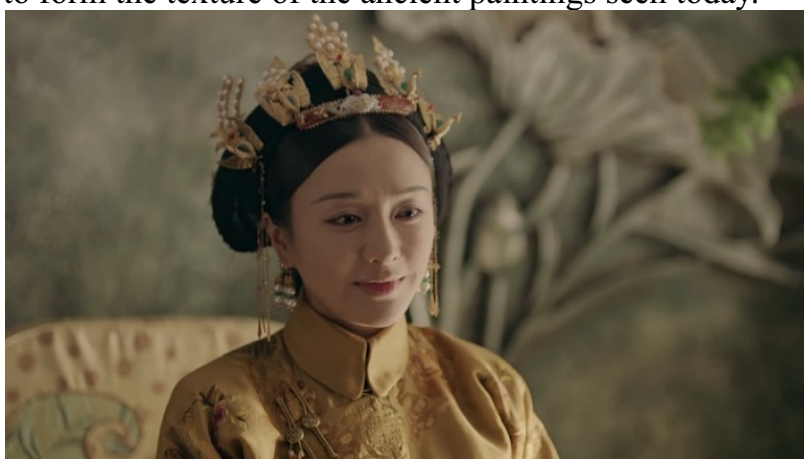

Figure 15: Picture tone 


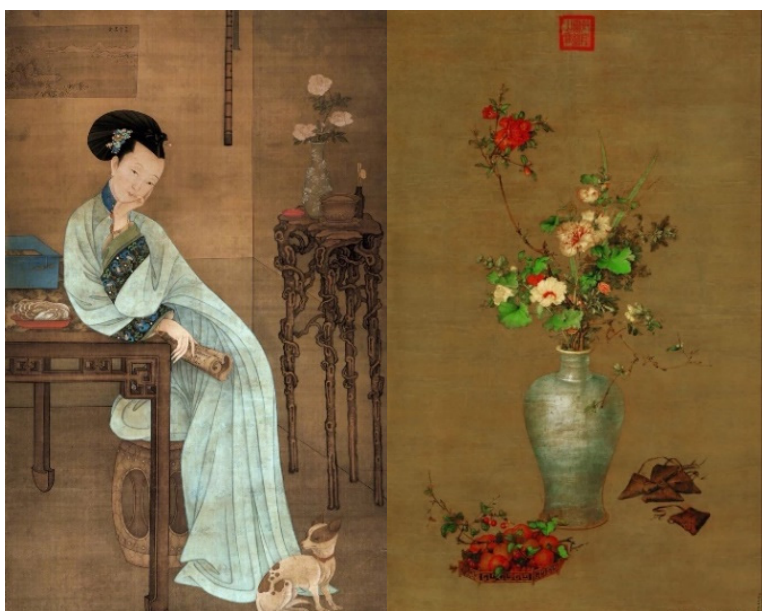

Figure 16: Qing Dynasty Ancient Paintings

\section{Conclusion}

In the report of the 19th National Congress of the Communist Party of China, Xi Jinping pointed out: "Culture is the soul of a country and a nation." The five thousand years of profound Chinese culture should be deeply imprinted in the blood of the Chinese people. We should be proud of our culture.

This TV series not only made the audience feel the charm of traditional culture, but also let the audience experience how traditional aesthetics is used in modern literary works. Although there are still some unresolved problems such as how to popularize traditional aesthetic common sense, but with this upsurge, more high-quality TV series will surely emerge in the future. These works will contribute to China's cultural construction.

\section{Foundation item}

Number: 512190105

Sponsor: Postgraduate Teaching Reform Project of Central South University

\section{REFERENCES}

1. Lang Ye.1999. Outline of Chinese Aesthetic History. Shanghai Renmin Chubanshe, Shanghai.

2. Danyuan Jin.2005. Television and Aesthetics: A New Theory of Television Aesthetic Culture. Xuelin Publishing House, Shanghai.

3. Xiaoshu Wang.2013. History of Chinese Aesthetic Culture: Yuan, Ming and Qing. Shanghai Classics Publishing House, Shanghai.

4. Zehou Li.2008. Four Lectures on Chinese Aesthetics and Aesthetics. SDX Joint Publishing Company, Shanghai.

5. Zhirong Zhu.2007. A Brief History of Chinese Aesthetics. Peking University Press, Beijing. 